tion period would be only $3 \%$ of the initial value, which is well within the assay error. Thus, concentration-dependent changes of theophylline clearance cannot be excluded as a possible cause for the differences in oral clearance that were observed between the single dose and chronic dose studies.

\section{Reference}

Efthimiou, H., Morgan, D. J., Ioannides-Demos, L., Raymond, K. \& McLean, A. J. (1984). Influence
S. VOŽEH \& F. FOLLATH

Division of Clinical Pharmacology, Department of Medicine, University Hospital, Kantonsspital, CH-4031 Basel, Switzerland

Received October 31, 1984, accepted January 14, 1985

of chronic dosing on theophylline clearance. $\mathrm{Br} . \mathrm{J}$. clin. Pharmac., 17, 525-530.

\title{
Influence of chronic dosing on theophylline clearance
}

Vožeh \& Follath (1985) have given two reasons in criticizing our exclusion of concentration dependence as a possible mechanism for the difference in oral clearances of theophylline (Efthimiou et al., 1984).

The first criticism, regarding the short sampling time compared with the terminal half-life, is valid when applied to the oral clearance determined from the first single oral dose. This criticism does not, however, apply to the oral clearance determined after chronic dosing because the calculation was performed on data obtained during a dosage interval at steady-state. The doubt regarding the oral clearance determined after the first single dose was, however, one of the reasons we repeated the clearance determination using intravenous infusion of theophylline and plateau drug levels.

The second criticism is based on the false premise that the intravenous loading dose was chosen on the basis of the clearance value found in the oral study. The size of the loading dose determines the plasma drug concentration at the end of the 20 min loading infusion and, as Vožeh \& Follath (1985) point out, for some time thereafter. Thus, Vožeh \& Follath (1985) argue that basing the intravenous loading dose on the oral clearance value will bias the apparent intravenous clearance value obtained towards the oral clearance value. The premise of this argument is false because, as stated in our paper (Efthimiou et al., 1984), the intravenous loading dose was calculated for each subject using a volume of distribution of $0.5 \mathrm{l} / \mathrm{kg}$, which is a

\section{References}

Efthimiou, H., Morgan, D. J., Ioannides-Demos, L., Raymond, K. \& McLean, A. J. (1984). Influence of chronic dosing on theophylline clearance. $\mathrm{Br} . J$. clin. Pharmac., 17, 525-530. literature value. The oral clearance value was used only in the calculation of the maintenance infusion rate and not the loading dose. Thus, the observed plateau theophylline levels and the resultant intravenous clearance values were not biased by the oral clearance values.

Inspection of our data shows that there was no systematic pattern in plasma levels following the loading dose in the intravenous clearance studies. In the acute phase, after the intravenous loading dose plasma theophylline levels approached steady-state from above in four subjects (subjects 1, 2, 4 and 5) and from below in the other two subjects. Similarly, in the chronic phase, steady-state was approached from above in four subjects (subjects 1-4) and from below in the other two subjects. This rules out the likelihood that there was a systematic deviation in the measured plateau levels from the 'true' plateau levels, as suggested by Vožeh \& Follath (1985). Thus, concentration dependent changes in theophylline clearance may reasonably be excluded as the cause for the differences in oral clearance.

\section{J. MORGAN \& K. RAYMOND \\ Victorian College of Pharmacy, 381 Royal}

Parade, Parkville, Victoria, Australia 3052

\section{A. J. McLEAN \\ Department of Clinical Pharmacology, Alfred \\ Hospital, Prahran, Victoria, Australia 3181}

Received January 8, 1985 , accepted January 14, 1985

Vožeh, S. \& Follath, F. (1985). Influence of chronic dosing on theophylline clearance. Br. J. clin. Pharmac., 19, 712-713. 